The Journal of

Thoracic and Cardiovascular

Surgery

Vol 127, No. 3, March 2004

\title{
Cross-circulation: A milestone in cardiac surgery
}

Vincent L. Gott, MD

Norman E. Shumway, $\mathrm{MD}^{\mathrm{b}}$

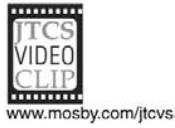

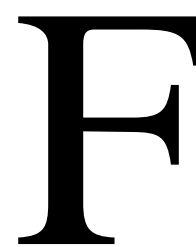

ifty years ago this month, Dr C. Walton Lillehei and his team performed their first repair of a ventricular septal defect (VSD) using cross-circulation. The cover photograph depicts that first operation performed on March 26, 1954. The 1-year-old child shared O+ blood type with his father, who served as the biological oxygenator. Dr Lillehei (wearing a headlight) is standing to the patient's left side; his first assistant is Dr Richard Varco. The child's father is on the adjacent operating room table. Femoral artery and femoral vein cannulas are seen emerging from the father's inguinal incision; his operative procedure was carried out by two of Dr Lillehei's surgical residents, Drs Herbert Warden and Morley Cohen. Dr Warden is standing behind Dr Lillehei and Dr Cohen is behind the scrub nurse. Dr J. B. Aust, an assistant resident, is standing to the right of Dr Varco and Dr Norman Shumway, another assistant resident, is standing behind Dr Varco. Dr Vincent Gott, a surgical intern, is to the left of Dr Shumway. The black Sigmamotor "finger-pump" is partially visible above Dr Cohen's head. The VSD was closed without a patch during 19 minutes of cross-circulation support; the aorta was not crossclamped and a cardiotomy sucker was not available for blood retrieval. This child did well for several days but developed pneumonia and died on the 11th postoperative day. One week later, Dr Lillehei and his team successfully closed a VSD in a 4-year-old boy using the same technique. This second patient survived and, at age 48, attended $\mathrm{Dr}$ Lillehei's 80th birthday celebration in October 1998. Between March 1954 and May 1955, Dr Lillehei operated on 45 children using cross-circulation and became the first surgeon to successfully repair VSD, tetralogy of Fallot, and atrioventricular canal defects. Remarkably, 28 (62\%) of these 45 children were discharged from the hospital, and 22 (49\%) were alive and well 30 years later. Parenthetically, a major cause of hospital mortality in this group of patients undergoing cross-circulation was heart block.

After Dr Lillehei's cross-circulation cases in the spring of 1954, another major development in open-heart surgery occurred on July 14, 1954, in Stockholm, where Dr Clarence Crafoord successfully removed an atrial myxoma using a disc oxygenator developed by Dr Åke Senning. The next surgical group in the United States to successfully repair a VSD was John Kirklin's team, using the Mayo-Gibbon screen oxygenator at the Mayo Clinic on May 22, 1955. Dr Lillehei switched to the DeWall-Lillehei bubble oxygenator May 13, 1955, and abandoned the cross-circulation technique. Remarkably, during 1955, only two centers in the world were performing open-heart surgery using cardiopulmonary bypass on a regularly scheduled basis; these two centers were just 90 miles apart in the state of Minnesota.

Drs Lillehei, Varco, Cohen, and Warden shared the Lasker award in 1955 for their seminal achievement. 